surface, or by a sphere with $p$ handles, or with $p$ holes, or by a plane curvilinear polygon generating a fuchsian group,* etc., and all these things are equivalent; by means of geometric or analytic transformation, by continuous deformation, by conformal representation, they change one into the other; and from all these representations the study of the algebraic form may derive help.

Those students who, following these suggestions, succeed in obtaining possession of the most varied instruments of research and in comprehending the science from all possible points of view, will attain therefrom the most brilliant success.

TURIN, February, 1891.

\title{
REPLY TO PROFESSOR SNYDER'S REVIEW OF STUDY'S GEOMETRIE DER DYNAMEN.
}

IN the January number of the BuLletin Professor V. Snyder, of Cornell University, lavishes praise and censure on the author of the book under his review, using vigorous terms in both respects. I beg leave to raise, in the present instance, some objections to this mode of criticism.

Preceding reviewers have successfully tried to convey to their readers, space permitting, an idea of the actual contents of the book in question. $\nmid$ Dr. Snyder takes a way of his own. He confines himself mainly to a consideration of the fundamental conceptions of the author's line geometry, as developed in the second half of the volume, and to an enumeration of subjects treated therein. While the latter is very incomplete, omitting, e. g., the most important part of the book (the appendix, referring to kinematics), the former reproduces, not so much the contents of the book itself as those of a paper by Professor E. Müller, and besides develops certain ideas dealing with non-euclidean geometry. By these means Professor Snyder endeavors to make the author's treatment "easier to understand."

\footnotetext{
* In particular for the elliptic form $(p=1)$, the annular surface, the parallelogram, the $(2,2)$ correspondence between two variables, etc.

$\uparrow$ Such reviews have been published by Professor Zindler, of Innsbruck, (Monatshefte für Mathematik und Physik, 1903-5 pp.), Professor Wirtinger, of Vienna, (Zeitschrift für Mathematik und Physik, vol. 49 (1903)-4 pp.), Professor Daniele, of Pavia, (Bolletino di bibliografia ecc., Dic. 1903-14 pp.).
} 
What help the secondary source quoted may offer, will be inferred from the fact that Dr. Müller, when he wrote his account, had before him only the first and smaller half of the volume, containing very little of the subject in question.

The reviewer's own development is introduced by the remark that " no hint is given the reader" by the author himself " regarding the origin of the new idea," and it concludes with the repeated assertion that "the development here traced is not mentioned by Professor Study" and that "perhaps he made no use of it." It is, however, pointed out in the preface that ideas of non-euclidean geometry were of considerable value to the writer - a " hint" which is, by the way, repeated in many places scattered through the book (see article "analogies" in the index) - and there is, moreover, a reference to pages 440 and 441, where the author confesses his indebtedness to other writers. In this place, to which the reviewer would also have been led if he had looked up the item " Non-Euclidean Geometry" in the index, he would have found immediately the very thing he is missing, with the exception of some errors, for which he alone is responsible. In the same place he would also have found mention of a paper by the author, bearing the date of 1900 , in which the topic is treated more fully.

The haste in which this review has been executed is further shown by Dr. Snyder's statement that the author's aplanar chain congruence is "dual to" the congruence of axes in a sheaf (bundle) of linear complexes. As a matter of fact the aplanar chain congruence is identical with the congruence of axes in a bundle of complexes (fulfilling certain inequalities) and is even defined as such, on page 323 (cited in the index). This curious mistake causes the astonishing statement that the aplanar chain congruence and its limiting cases are "fully discussed" while the congruence of axes receives, comparatively, "too little attention"! To appreciate this confusion rightly, it is to be noticed that the congruence whose very definition is distorted by the critic, is one of the fundamental conceptions of the theory in question (treated in more than eighty pages, and dealt with at length also, under the same mode of generation, in the previous literature cited by the reviewer). But behold one more example!

For certain purposes the author thought it appropriate to count each straight line twice and accordingly cover the line space with two "sheets" (pages 224, 231-233). This simple 
idea, which is, of course, totally different from the so-called orientation of a straight line ( $i$. e., the discrimination of its two directions), Professor Snyder explains as follows: He first considers a (real) line, in the finite domain, as being given by two points $\lambda_{1}, \lambda_{2}$ on a sphere. Then " $i n$ order to include all the lines of space" he makes the radius of the sphere "infinitely large" and goes on to say: "In order to distinguish between the two points $\lambda_{1}, \lambda_{2}$ on the surface of the sphere and insure that the line connecting them does not lie entirely at infinity, it is convenient to think of all the lines of space being double, or arranged in two sheets." (The italics are the present writer's.)

These examples will suffice to give the reader an idea of the oversights and errors that are numerous in this review.

Professor Snyder has also seen fit to make comments on the author's style, including one of a personal nature. That the text is hard and the reasoning sometimes complicated the writer does not seek to deny.* He cannot help regretting, however, that the reviewer did not find it worth his while to overcome even the lesser difficulties before publishing his review. Under these circumstances the words of praise which are distributed with liberal hand will have little weight.

Bons, April, 1904.

E. STudy.

My statement that the congruence $(3,2)$ is dual to the congruence of axes in a linear sheaf is erroneous ; this fact however does not affect the validity of the subsequent part of my review. My definition of the congruence $(3,2)$ and the inter-

* The chief hindrance to the reader lies probably in the terminology. It has already been conceded in the preface that the terminology is actually somewhat too extensive (a fact not mentioned by the reviewer). Dr. Snyder's statement, however, that the number of "new" terms in the first part of the volume alone exceeds one hundred, may be literally correct and yet fail to do justice to the writer. Some expressions are to be kept in memory for a few pages only, others are obvious derivatives from preceding terms, and others again are as a matter of course transferred from one system of constructions to the next. To take an example: It would be hardly fair to say that nine new terms are contained in the words : Keil, Quirl, Linien-Kreuz; eigentlicher Keil, eigentlicher Quirl, eigentliches Linien-Kreuz ; uneigentlicher Keil, uneigentlicher Quirl, uneigentliches Linien-Kreuz. Some of my colleagues, who kindly did the counting for me, are of opinion that with a reasonable method of counting the "new" terms in the first part (covering $115 \mathrm{pp}$.) may be estimated to amount to 40 or 50 - a number still too large, no doubt. 
pretation of the symbols employed are taken literally from Professor Study's book, page 461 .

The transition from $G_{16}$ to $G_{17}$ was discussed by Professor Klein in the lecture of June 15, 1903, of his course on the encyclopedia of geometry. My own explanation would have been improved had I further quoted from this lecture.

In regard to Professor Müller's paper I will add that the "first and smaller half" of Professor Study's volume contains pages 1-240. The entire development of $\varepsilon$ and of $G_{17}$ is contained in pages $225-240$.

I regret having used the word self-conscious. While I desired to emphasize that the book was hard to read on account of the style, I had neither cause nor inclination to make any personal reflection on its author.

Virgil SNyder.

\section{NOTES.}

THE sessions of the mathematical department of the international congress of science at St. Louis, will open on Tuesday, September 20, with addresses by Professors MAXIME Bôcher and James Pierpont. Professor Bôcher's address will be of a theoretical and critical character ; Professor Pierpont will present a historical resume of mathematical progress in the nineteenth century. On the following days of the meeting (Wednesday-Friday) the three sections of the department will meet separately, but at different hours. The principal speakers before the sections will be: Section 1, analysis and algebra, Professors E. Picard and H. Maschke; Section 2, geometry, Professor G. Darboux and Dr. Edward Kasner ; Section 3, applied mathematics, Professors H. Poincare and L. BoltzMANN. A detailed announcement of titles of the several addresses, arrangement of hours, etc., will be made in June by the exposition committee on congresses, of which Professor Simon Newсомв is president.

The National academy of sciences held its annual meeting at Washington, D. C., April 19-23. The only mathematical paper was by Mr. C. S. PeIrce, "On the simplest branches of mathematics." The officers of the preceding year were re- 